\title{
The Dual Face of HOF in High-Risk Organizations
}

\author{
Corinne Bieder
}

\begin{abstract}
High-risk organizations commonly acknowledge the importance of human and organizational factors (HOF). However, in practice the role played by HOF specialists and their share of voice varies dramatically from one organization to another. Within organizations themselves, there are some recurrent tensions around $\mathrm{HOF}$ and the role HOF specialists are understood to play. This delicate situation seems to partly stem from the gap between conventional wisdom on HOF in highrisk organizations and how HOF specialists see HOF and their role and contribution to organizations. Exploring this dual face of HOF and trying to better understand where it comes from may help to reduce misunderstandings and suggest ways forward to build on the remaining inevitable organizational contradictions to improve the way HOF are considered in high-risk industries.
\end{abstract}

Keywords Human factors $\cdot$ Organizational factors $\cdot$ Safety $\cdot$ Complexity

\section{Introduction}

Although the importance of human and organizational factors (HOF) for safety is widely and commonly acknowledged in high-risk organizations, the reality is more qualified as to how this 'importance' translates into practice. Drawing a general picture that would pretend to be representative of all high-risk organizations or even of all parts of a given organization would be oversimplifying a diverse reality. In addition, the way HOF are taken into account varies in time, along with the context, the people and probably many other factors that would be worth exploring. However, in some parts of some organizations, as the issues raised by FonCSI's industrial partners go to show, there is a recurrent emergence of tensions around HOF and the role HOF specialists are understood to play. These tensions seem to partly stem from the gap between conventional wisdom on HOF in high-risk organizations and how HOF specialists see HOF and their role and contribution to organizations. Exploring

\footnotetext{
C. Bieder $(\bowtie)$

ENAC, University of Toulouse, Toulouse, France

e-mail: corinne.bieder@enac.fr 
the gap between this dual face of HOF and trying to characterize it may be a starting point for envisaging ways forward to improve the way HOF are considered in highrisk industries.

\section{How HOF Specialists See HOF and How They See their Role}

Human and organizational factors are understood in many different ways, including among so-called HOF specialists depending on their earlier education, background, experience... The emphasis may vary from one HOF specialist to another (e.g. individual or organizational mechanisms, psychological, ergonomics or more social aspects). However, it is commonly agreed that overall, HOF are both a specific body of scientific knowledge on a range of aspects such as human cognition, physiology, organizational mechanisms and a set of scientific methodologies to apprehend real work situations. This distinction between what is at play in real work situations and a theoretical view of how work should be done or how organizations should function is at the core of HOF.

This specific scientific and methodological background leads HOF specialists to consider themselves as experts. Indeed, this knowledge is not commonly passed on in educational or training paths other than the social sciences. In a sense, HOF specialists see their role as the experts of reality, the spokespersons for the distinction between real practices and theoretical processes and procedures, between organizational charts and organizations considered as living 'bodies'. In other words, they see their role as the constant reality bell in managers and decision-makers minds. By bringing reality to the surface, although it is reality seen through the lenses of their conceptual, theoretical and methodological background, they see their role as the voice of reality, the one that everyone should absolutely listen to and consider, at all levels of the organization including the highest echelons, to acknowledge these differences and take benefits from them to enhance safety and more generally to improve the overall performance.

Even though HOF specialists may initially intervene to enhance safety, analyzing how work is done in reality and how organizations actually function goes beyond the sole safety dimension. In this respect, they see their scope as broader than just safety, encompassing all aspects of the way the organization functions and is managed.

Thus, they see their positioning as a core part of business management to improve not only safety but the global performance of an organization, even if in high-risk domains, safety is a key dimension of the global performance. However, such positioning may appear to some extent in contradiction with the claim of expert knowledge. Indeed, as characterized by Ardoino [1], the expert is called upon to solve a problem with limited scope for which the expert is known to have high levels of knowledge and competence. In contrast, the positioning of HOF specialists would correspond to that of consultant [1] (or process facilitator as called by Schein [5]), 
meaning they intervene with the aim of modifying or changing representations, attitudes and the like through longer interventions and joint work with the 'client', including on the problem statement and request.

Ironically, although HOF specialists claim to be experts in how reality works, how HOF specialists see themselves could be considered a description of how HOF specialists should be seen, rather than how they are seen in reality. Indeed, decisionmakers and top managers seem to have different views on $\mathrm{HOF}$ and the role of $\mathrm{HOF}$ specialists in high-risk organizations, at least according to what HOF specialists perceive.

\section{How Decision Makers and Top Management See HOF and the Role of HOF Specialists}

One of the reasons for the gap between how HOF specialists see their role and how managers see it lies in their different views on HOF. If HOF specialists see the reality of work through their social science lenses, managers, whatever their level, see reality through their managerial body of knowledge and tools lenses. Again, generalizing how managers see HOF is too simplistic and caricatural an approach, but it helps to point out where some of the current difficulties, misunderstandings and frustrations come from, and to envisage possible ways forward. Conventional wisdom on HOF in high-risk industries assumes, among others, that there can be a good organization (understood as organizational structure), that everything can be described and prescribed in processes and procedures, and that if everybody complies with these requirements, it is the best way to ensure safety [3]. Indeed, this is how quality is ensured.

With this understanding of HOF in mind, HOF specialists are seen as experts having established knowledge on a limited defined scope [1, 5], human and organizational aspects, able to help solving problems with the organizational structure or processes or procedures, through quick interventions aiming at improving them or providing knowledge/data to improve them. They can act as a support to the implementation of the current management model through inputs to improve or develop operational processes and procedures, sometimes even organizational structural settings that are obviously directly related to safety.

Another aspect of their role is to serve as an 'alibi' for external justification. By having identified HOF specialists, the organization can claim it takes HOF into account, whatever their actual role and influence.

Regarding their primary role, their scope is naturally limited to the improvement or further development of how HOF are seen (i.e. good procedures, processes, organizational structure, selection, training...) in order to enhance safety.

Their positioning is therefore a side function supporting business which is the core function as it is meant, taught, thought in business training (i.e. mainly production and efficiency). 
Whereas the ambition of HOF specialists could be understood as revolutionary with regard to how organizations are run and managed, what managers expect from HOF specialists is far more modest and limited in scope. It comes down to providing support to improve their current safety management practices, which means actionable recommendations to improve prescriptions, which HOF specialists are most often reluctant to formulate. Indeed, HOF specialists consider, with their viewpoint strongly anchored in the reality of work, that prescriptions cannot be developed exclusively top-down. Instead, they claim that the operators themselves, the ones who have the best field expertise and who will be using the prescriptions, should be involved in their development.

Eventually, significant tensions exist around how the role of HOF specialists is perceived by HOF specialists themselves and managers respectively. To take an engineering metaphor, from the point of view of managers, HOF specialists should focus on the refinement of the human-machine interface rather than on the definition of the functionalities of a technical system. To take another metaphor, they should be good at reporting minor facts of the world, like Clark Kent does, rather than trying to save the world as Superman does. Yet, functionality and interface both influence each other and also ultimately what a socio-technical system will do and how it will perform... Just as Clark Kent is part of Superman and Superman is part of Clark Kent....

\section{How to Make these Tensions Constructive: Reconciling Superman and Clark Kent?}

Is there a constructive way forward to handle this significant gap between the two faces of HOF? Would it make sense to try and turn Superman into Clark Kent or conversely, to try and turn Clark Kent into Superman? Would the world be better if these two faces became a single one?

Coming back to the (at least) dual face of HOF, shedding light on these questions would definitely require further investigation and refinement in several areas. As mentioned earlier, a first area would be to get away from a single homogeneous category when referring to $\mathrm{HOF}$ as well as to HOF specialists. The way they perceive themselves as well as the way they believe they are perceived may be significantly diverse. Likewise, managers are not a single homogeneous lot and would deserve a refined categorization. Their understanding of $\mathrm{HOF}$ and of the role of HOF specialists may vary dramatically with a number of factors to be investigated.

Nevertheless, HOF can be characterized as a specific way to look at work and organizations (a more realistic one would claim HOF specialists). In a sense, $\mathrm{HOF}$ can be seen as a way to make progress in ignorance by bringing to the surface and recognizing uncertainty and contradictions in real work situations, where the dominating management models often tend to seek to eliminate uncertainty and contradictions. If, currently, both are seen as competing with one another and trying 
to impose their respective view, leading to frustration, could other ways forward be explored?

Integration of HOF into engineering models, business models, etc., is often suggested (see Laroche, chapter "The Languages of Safety", this volume). Yet, integration leads to giving up the diversity of views and approaches, and ultimately leads to holism rather than reflecting the complexity of reality. Yet, it is precisely this complexity of reality that HOF specialists try hard to advocate in their daily work by highlighting the interrelations between individuals and/or organizational entities, how they organize themselves as well as the antagonistic objectives and characteristics at play. In this respect, integrating HOF into other dimensions, and contenting oneself with it, would be selling HOF's soul to the devil. As would be trying to impose HOF views on the overall way the organization is managed, thereby killing the requisite variety. Acknowledging contradictions, complexity, uncertainties, in a sense the need for system thinking, is part of HOF experience, if not at the core of it, and not trying to eliminate all of the competitive and antagonistic characteristics between the parts is precisely at the core of system thinking [4].

More exchanges between HOF specialists and managers, developing a better understanding of their respective worlds and views could possibly help to resolve unnecessary contradictions (not all contradictions) and could be a middle way to explore between the integration and missionary extremes. For a start, it would help to adjust the type of interventions and postures of HOF specialists to the context and conditions, between content expert, process facilitator [5] or a more political action through generic "speech" and models with a performative aim to change representations on the role of humans and organizations in safety [2].

Nevertheless, the inevitable remaining contradictions will perpetrate, at least to some extent, the dual face of HOF and its ambivalent effect. HOF specialists will continue to propose ways forward, although they know there is no definite and sustainable solution despite what managers believe and expect. They will thereby continue to create disappointment and frustration at the manager level, but at the same time, will continue to claim they were not given sufficient leeway to act and that more interventions are needed. A tricky simultaneously vicious and virtuous circle!

\section{References}

1. J. Ardoino, Les postures (ou impostures) respectives du chercheur, de l'expert et du consultant. Les nouvelles formes de la recherche en éducation 2, 79-87 (1990)

2. P. Bourdieu, Décrire et prescrire [Note sur les conditions de possibilité et les limites de l'efficacité politique], in Actes de la recherche en sciences sociales, vol. 38, mai 1981. La représentation politique-2 (1981), pp. 69-73. https://doi.org/10.3406/arss.1981.2120, https://www.persee.fr/ doc/arss_0335-5322_1981_num_38_1_2120

3. IRSN, Les Facteurs Organisationnels et Humains de la gestion des risques: idées reçues, idées déçues. Rapport DSR n438 (2011) 
4. E. Morin, From the concept of system to the paradigm of complexity. J. Soc. Evol. Syst. 15(4), 371-385 (1992)

5. E.H. Schein, The role of the consultant: content expert or process facilitator? J. Couns. Dev. 56(6), 339-343 (1978)

Open Access This chapter is licensed under the terms of the Creative Commons Attribution 4.0 International License (http://creativecommons.org/licenses/by/4.0/), which permits use, sharing, adaptation, distribution and reproduction in any medium or format, as long as you give appropriate credit to the original author(s) and the source, provide a link to the Creative Commons license and indicate if changes were made.

The images or other third party material in this chapter are included in the chapter's Creative Commons license, unless indicated otherwise in a credit line to the material. If material is not included in the chapter's Creative Commons license and your intended use is not permitted by statutory regulation or exceeds the permitted use, you will need to obtain permission directly from the copyright holder.

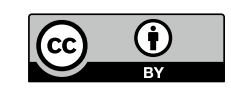

